\title{
Designing the urban commons through gender and nature-based approach. A renewed project for public space in times of crisis.
}

\author{
Kevin Santus \\ DAStU, Politecnico of Milan, Italy \\ kevin.santus@polimi.it
}

\section{Arianna Scaioli}

DAStU, Politecnico of Milan, Italy ariannaluisa.scaioli@polimi.it

\begin{abstract}
Il progetto dello spazio pubblico contemporaneo può accogliere le nuove istanze della società contemporanea, incorporando valori e necessità proprie dell'epoca attuale. II contributo ha lo scopo di presentare la possibilità di un approccio trasversale, in cui gli ideali di una società ecologica ed equa siano integrati nello spazio e nelle sue fasi di progettazione.

Questo metodo è disvelato attraverso l'utilizzo di nature-based solutions e gender-sensitive approach, applicati all'interno di processi di rigenerazione urbana di aree marginali, considerate come contesti fertili, in cui si denota una sovrapposizione di problematiche ambientali legate al cambiamento climatico e disuguaglianze di genere. Attraverso la presentazione di due casi studio, verranno quindi mostrate delle soluzioni applicative delle strategie menzionate, in cui il progetto non è subordinato alla sola costruzione della forma, bensì intreccia valori etici ed estetici nella costruzione di uno spazio collettivo.
\end{abstract}

\section{Parole chiave}

Spazi collettivi, rigenerazione, resilienza sociale/ambientale, gender sensitive approach, nature-based solutions

\begin{abstract}
The design of the contemporary public space can include the new needs of society, incorporating the values of the current era. The contribution aims to present the possibility of a transversal approach, in which the ideals of an ecological and fair society are integrated into space and in its design phases.

This method is revealed through the use of nature-based solutions and gender-sensitive approach, applied within urban regeneration processes of marginal areas, considered fertile contexts, in which there is an overlap of environmental problems linked to climate change and gender inequalities. The article will display the application of the aforementioned strategies through the presentation of two case studies, in which the project is not subordinated to the production of the form but rather intertwines ethical and aesthetic values in the construction of common space.
\end{abstract}

\section{Keywords}

Urban commons, regeneration, social/environmental resilience, gender sensitive approach, nature-based solutions 


\section{Introduction}

Contemporary cities are facing an increasing systemic fragility due to recurring climate hazards, social injustice, economic crisis, and pandemics, in which the conflictual relationship within societies and the environment is catalyzed and intensified.

On top of that, this paper assumes the recognition that climate change does not affect everyone symmetrically. Disasters increase existing gender disparities, as women are more vulnerable to the effects of emergencies, intensifying the marginality of some spatial relationships and reducing the capability to answer (GIZ, UN-Habitat \& CenderCC, 2015; Women4Climate Report, 2019).

This condition implies a necessary rethinking of relationships among social and spatial models (Stiegler, 2019; Bulkeley, 2013), where the project must be investigated both in its transition and in its capacity to respond transversally and transcalarly to the systemic crisis.

The paper, encompassing the notion of assemblage thinking (Deleuze \& Guattari, 1987) for understanding the complexity of the city problems by emphasizing the relations between sociality and spatiality at different scales, aims to present design strategies where Nature-based solutions (NBS) and a Gender-sensitive approach (GSA) interact, to define a project for common spaces that embodies social and environmental resilience toward a prepared- ness perspective, assuming both the tangible and the intangible design sphere.

This article can be understood as part of two broader researches, where the common interest is to bring a reflection on the necessity of weaving together environmental and social values to re-conceptualize a resilient and inclusive design approach. Specifically, the study focuses on regeneration processes in urban areas where the effects of climate change seem to worsen (Kabisch et al., 2017), displaying a new contradictory geography characterized by substantial social inequalities, defining unstable socio-spatial contexts (Pasqui, 2020). Hence, alongside a reflection on the social phenomena, it is necessary to develop a critical architectural approach that, starting from these crisis factors, promotes an operational framework to rethink the everyday living spaces and ultimately stimulates a reflection on the architect's role in framing this process.

\section{Method of investigation}

Starting from some initiatives promoted by the European Union (New European Bauhaus, Green New Deal) and the United Nations (SDGs 2030, Climate Actions for Cities, Gender Equality Strategy 20202025), the article frames the urgency to operate and rethink the public realm through a cross-cutting design strategy that integrates NBS and CSA. 

passing a stratification of both tangible and intangible values. This richness emerges from the intersection between environmental and social justice, understanding how these concepts can be implemented and translated in the construction of the contemporary common space, embodying the current values of climate resiliency and social equality. In this sense, the authors consider NBS and CSA as possible design tools to rethink and adapt public and common spaces.

Specifically, the selection of the case studies focuses on European projects in which both environmental and social values were considered throughout the entire design process with the aim of regenerating a neglected urban area, also rethinking an urban fragment of landscape. Both located in Spain, they present similar climate environments and climate issues (e.g. heat island effect, drought, etc.), and are settled in marginal urban areas with comparable social and spatial settings. The Spanish context has also been investigated due to the fertile path traced by different municipalities to incorporate and develop a design process mainstreaming a gender approach from the very beginning (The Plan for Gender Justice 2016-2020 in Barcelona, The strategic plan
The two selected projects, used as an instrument to display the cross-cutting design strategy, are 'Ecopolis plaza' by Ecosistema Urbano, and 'Plaça d'en Baró' by the Spanish studio Equal Saree.

Specifically, the article contributes to the debate about the renegotiation of urban commons, assuming climatic and social issues to reflect upon the necessity of a cross-cutting design strategy for rethinking public spaces, weaving together tenets of environmental and social justice both in their tangible and intangible expression.

\section{Thematic Framework}

The consequences of the environmental and climatic crisis are changing the balance of life on the planet (Crutzen, 2005), producing a growing onset of risks, accentuating pre-existing fragilities. Accordingly, the promotion of a systematic, sustainable project, following the three pillars of sustainability social, environmental, and economic - assumes the recognition that climate change does not affect everyone symmetrically (Terry, 2009), but it catalyzes already existing social and gender inequalities (Hawken, 2017).

In this broad framework, public spaces face significant challenges, often configured as a 'theatre of conflict' rather than collective practices and social exchange, losing its true character, that is, "a common space in which general social trends come to light, but also a space that resounds with highly specific local factors, actors and claims." (Avermaete, 2009. p. 61).

Regarding climate-related issues, a solid ecological attitude and necessity are spreading throughout the world, urging for proper design tools that can adapt to the urban environment, making the relationship between people and the environment closer. Expressly, the article assumes NBS as a design tool that shows positive effects on reducing climate effects, improving the urban microclimate, and increasing urban biodiversity (Kabisch et al., 2017). 


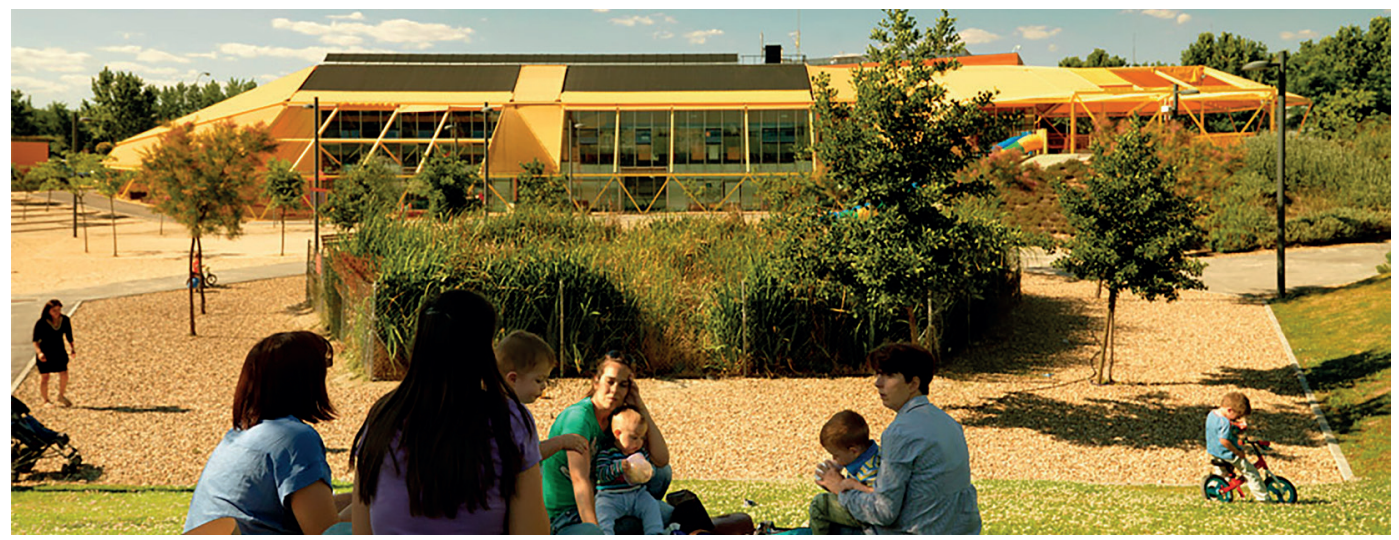

Fig. 1 - An urban common space. Design \& Ph: Ecosistema Urbano

In addition, these solutions play a significant role in constructing spaces capable of resisting risks such as floods or rainstorms, which affect urbanized areas in an increasingly systematic manner.

Therefore, a resilient, shared, and fair regeneration for a new paradigm of inhabiting public spaces starts from believing that environmental justice can only be achieved through social justice (Terry, 2009). In this sense, the empowerment of vulnerable groups can become the driving force behind this transition towards self-reliant communities (Shuman, 2000), building local knowledge and a sense of care that could foster a condition of greater preparedness to face future crises (Lakoff, 2007).

Accordingly, the paper aims to reflect on socio-spatial relations starting from a critical investigation of design experiences, which are set as examples for an alternative approach towards architecture whose characteristics have now become unsustainable.

Yasmeen Lari, a Pakistani architect, states the necessity to pursue a "zero-carbon, zero-waste architecture" that empower poor and vulnerable communities. This ethos sets the premises for Lari's "barefoot social architecture" philosophy which focuses on the 99 percent of the population and aims to build self-reliant communities able to face environmental disasters. The presented contribution takes some considerations starting from broader de- sign experiences, distant in time and space, showing how this paradigm shift, linked to the design of spaces for commons, is due to an ever-greater sensitivity towards values-driven design approaches.

Exemplary, in this sense, are the reflections synthesized in Architecture for the poor by Hassan Fathy; Anupama Kundoo's work for the experimental city of Auroville with the project of the Line of Goodwill that is centred around NBS and the notion of coexistence of different people; Anna Heringer whose mission is to improve the living conditions of communities through a sustainable and inclusive design approach; the community-driven approach adopted by Space\&Matter, where, especially in the Schoonschip neighbourhood, ecology and people are the fundamentals to structure new parts of the city, establishing a continuity with the urban landscape; many European funded projects, such as La Fábrica de toda la vida, in which the regeneration of big complex of buildings is assumed as social possibility of reactivation. With these perspectives, concepts like "resilience", "the right to the city" (Lefebvre, 1968), and the "ethics of care" (Tronto, 2005) are becoming central in the architectural debate, encouraging the construction of renewed narratives and practices of resistance to redesign and reclaim public and common spaces towards a democratic, humanistic and ecological architecture and landscape. 


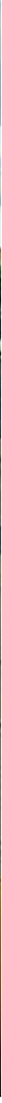

Fig. 2 - Social gathering. Design \& Ph: Ecosistema Urbano

Ecopolis Plaza: urban commons for a resilient and pedagogical space

The project Ecopolis Plaza (fig. 1), situated in the outskirts of Madrid's periphery displays an urban project where the formal experimentation integrates ecology and social perspectives in a common everyday space.

Settled in Rivas-Vaciamadrid, within the metropolitan margin of the Spanish capital, the area, before the intervention, lacked almost entirely of public areas, so the studio was selected to design a common space that could create an encounter point for the
The aim of the studio Ecosistema Urbano was to integrate the idea of sustainability within the commonplace, to make it an instrument to increase the awareness of sustainability. With this perspective, the site's regeneration was composed of an open common ground and a public school.

The project displays the construction of an urban ecosystem designed to fulfil all people's social rights. The designed space, seen as a resource within the topic of the urban commons, is considered both a social product and a prerequisite for inclusion and cohesion (Stavrides, 2016). This concept emerges through the design of spaces that present dif- 


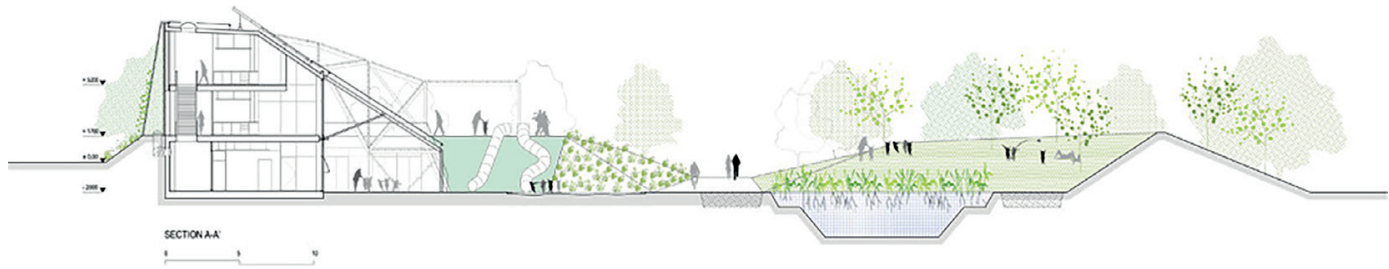

Fig. 3 -Renewed ground project. Design \& Ph: Ecosistema Urbano

HIDROLUTION SYSTEM FMF (FLOATING MACROPHYTES FILTER)

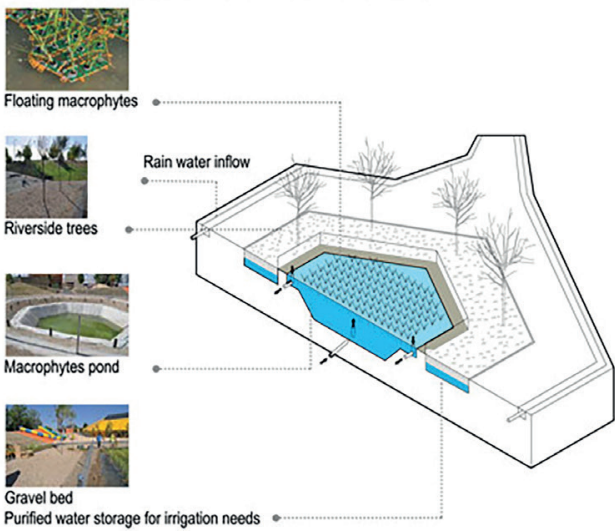

CIRCULATION DIAGRAM

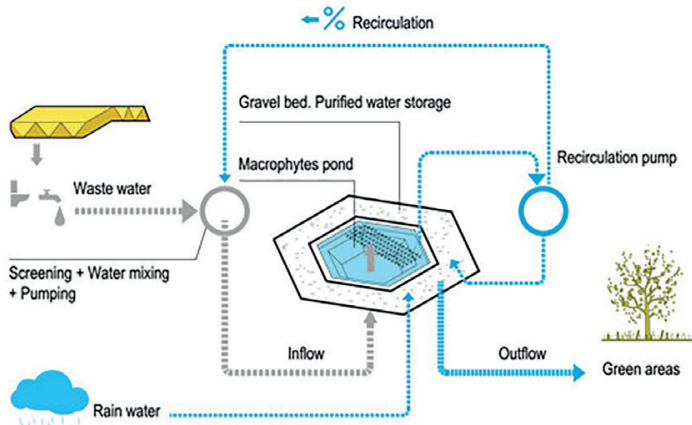

Fig. 4 -Definition of a close cycle for the site. Design \& Ph: Ecosistema Urbano

ferent connotations according to users' activities, ranging from childhood to adulthood.

In addition, to embody the sustainable idea in everyday life, the studio approached the project with a $\mathrm{Na}$ ture-based design, using nature in a dualistic way. To begin with, it is used to design a new landscape working with the ground, where the artificial topography protects the space from the external industrial and infrastructural environment, functioning as an urban natural filter (fig. 3), showcasing great attention to the aspects of accessibility and safety.

In addition, the juxtaposition of a water spot is used to naturally purify the water from the building, de- signing a small lagoon where the recycled water is used to irrigate the gardens of the project (fig. 4) and so to contrast drought periods, increasingly frequent in the Mediterranean area. Through this NBS, the project structures, on the one hand, a close cycle within the project and, at the same time, contributes to reshaping the aesthetic of the marginal area. Specifically, from a social and gendered perspective, the project developed the space as an 'open environmental classroom' for children, aiming to construct a safe, accessible and inclusive learning environment for families and local communities that could also benefit future generations. 


\section{Plaça d'en Baró: urban commons as a renewed space of wellbeing and emancipation}

The Plaça d'en Baró, in Santa Coloma de Gramenet (fig. 5) is located in a marginal and densely populated municipality of the metropolitan area of Barcelona. It is part of a municipal proposal Pedestrian district: Riu Nord to foster a greater habitability of public and common spaces by creating a wider network of streets and squares with various uses, encompassing a social and gendered perspective. Prior to the regeneration process, this area was considered by the users, especially women, children and the elderly, as neglected, closed and insecure.

The project, by the feminist architecture firm Equal Saree, aimed to regenerate a public square, through a participatory design activity within the neighborhood, involving boys and girls in a co-creative process to rethink the common spaces, hosting new activities for children and the local community. (fig. 6) Significantly, a gendered approach has been introduced from the beginning to generate a plaza open to the neighborhood, which, through various uses, tries to answer the different needs of future citizens. The result is an inclusive and safe space that participates and plays an active role in reconstructing a social narrative of public spaces in peripheral areas. Accordingly, the project develops a spatial configuration to answer its three main objectives. through the creation of different environments, encourages alternative ways of play in a safe environment, where adults can rest but be present in those moments. The designed spaces present similarities in dimensions not to generate a hierarchic approach to its use, nor to categorize groups of people, fostering equal participation. The second is the Caring Square, which embodies the values of care and inclusion, translating them into space, both from a social and an environmental perspective. It is focused on the wellbeing of families and children, with a shaded central space for social interaction.

The last is the Vital Square which focuses on social cohesion and contributes to the increased sense of safety in the neighborhood, opening up the perimeter to foster a complete permeability. In this sense, starting from the perception of users, which identifies in corners and dark residual spaces unsafe spaces to avoid, the design aims to propose a multitude of different and lightened paths that connect the square with the urban fabric around.

Besides these objectives, the studio Equal Saree had to face environmental issues connected to the heat island effect. Indeed, before the regeneration, the area was affected by this climate-related problem, also due to the general impermeability of the soil and the dense fabric around it. This issue interfered with the quality of the common space, which was underused and with a low environmental quality.

Because of that, NBS were implemented, introducing plants and vegetation that could reduce the heat-island effect, raising the wellbeing of the space and, at the same time, making the square more permeable to rainwater (fig. 8). Moreover, through the ground design, the architects structure a renewed urban landscape entangled with new ecological and physical needs. The vegetation within the project defines a renewed ecosystem that impacts the aesthetic of the square, where a combination of evergreen trees and deciduous ones blends with the mineral urban landscape. 


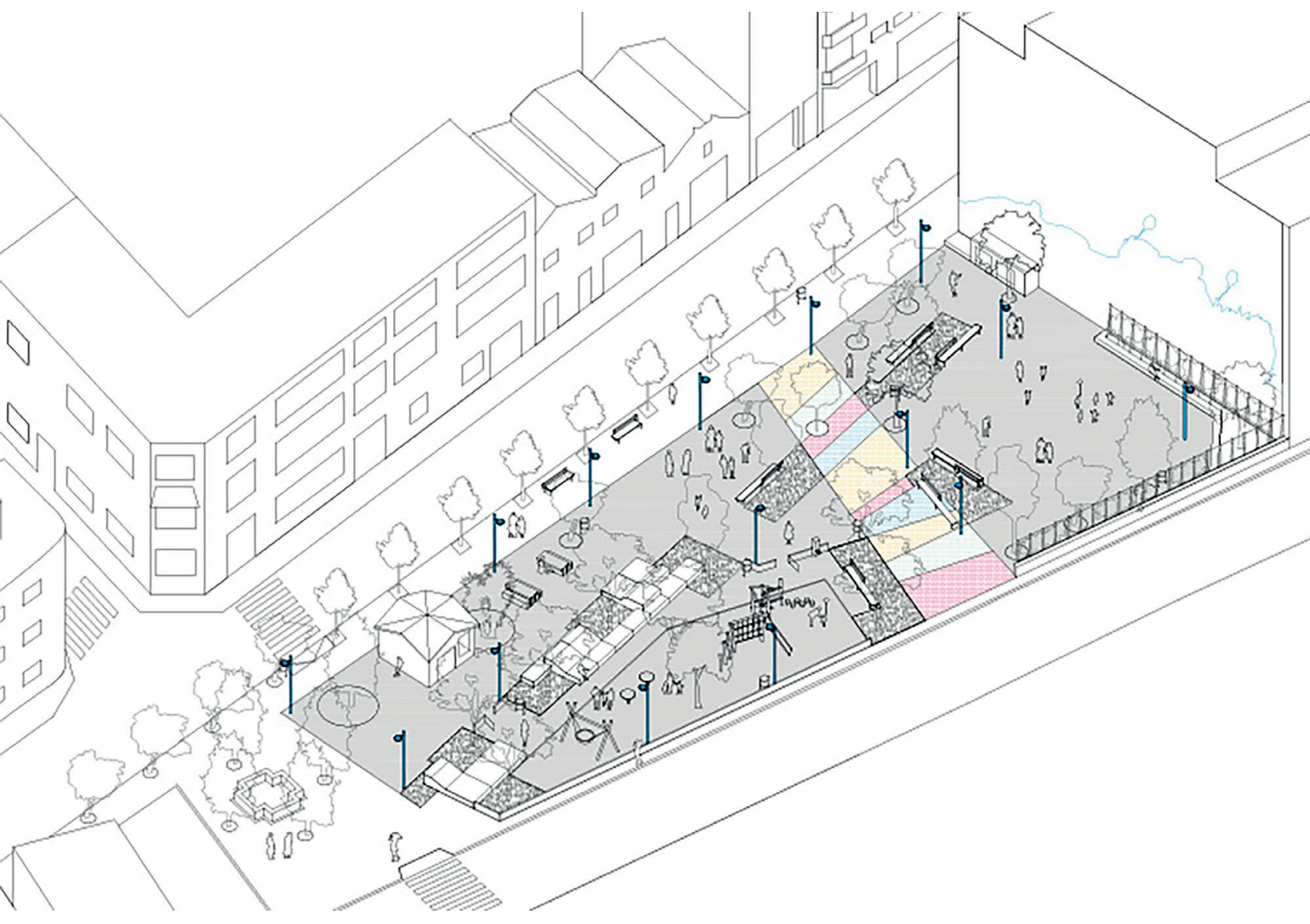

Fig. 5 - General axonometry of the project. Design \& Ph: Equal Saree

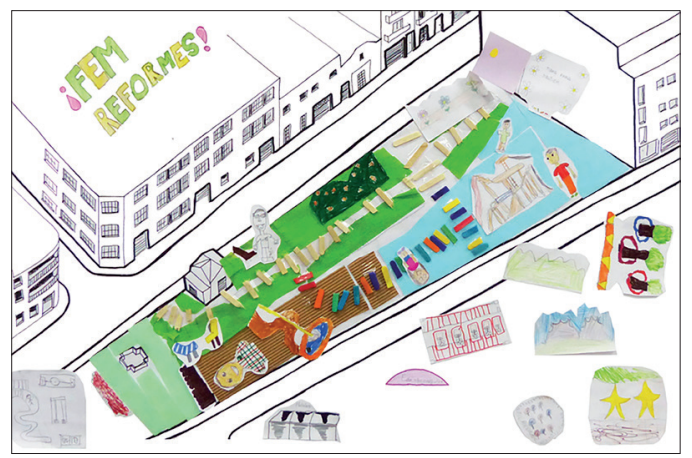

Fig. 6 - Design by students of the Torre Balldovina school. Ph: Same saree

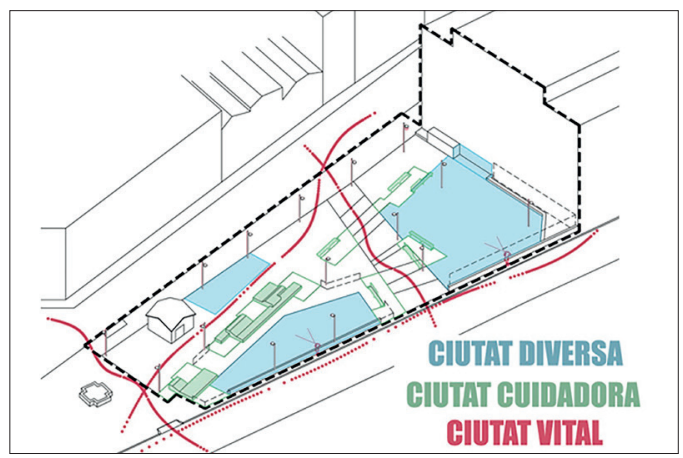

Fig. 7 -Design strategy.

Design \& Ph: Equal Saree 


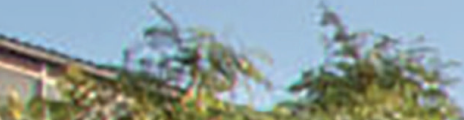

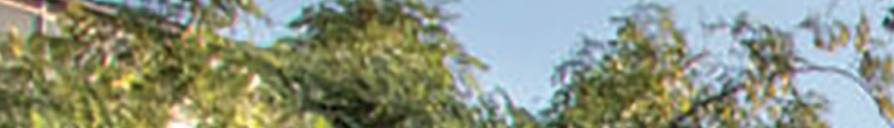

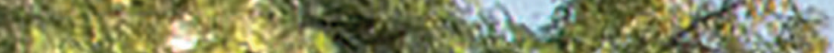

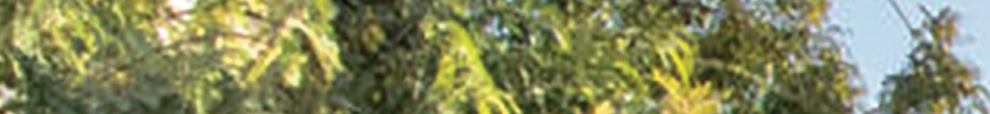
2.

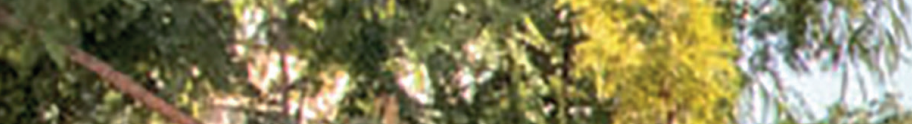

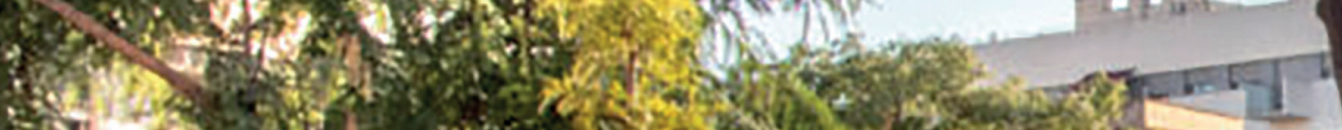

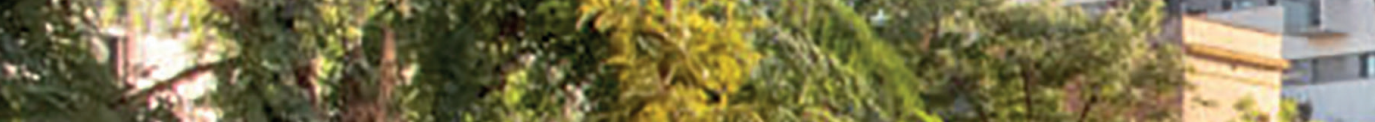
s.m.

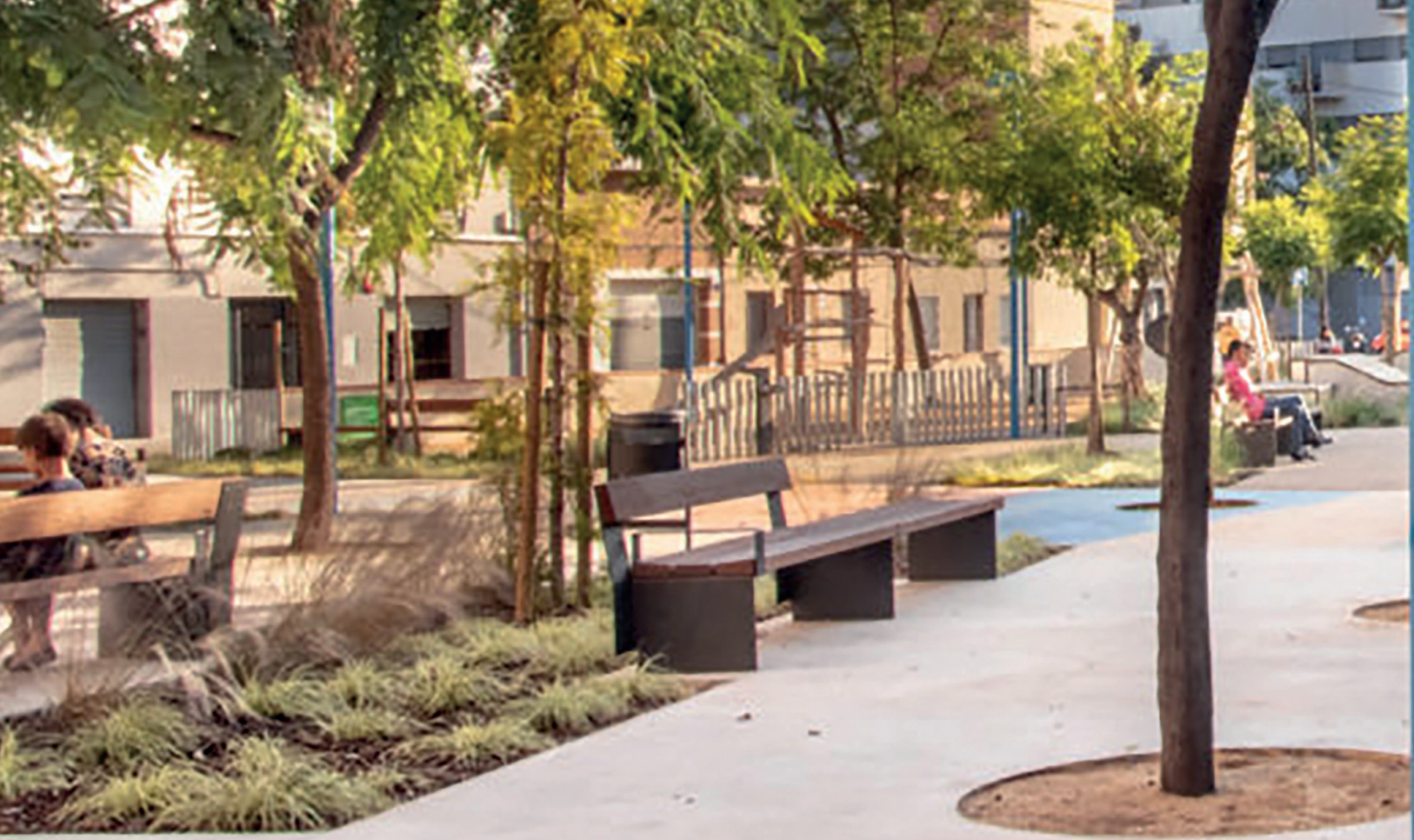

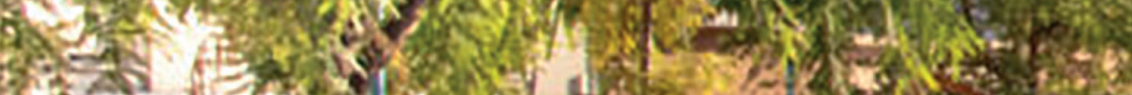
की

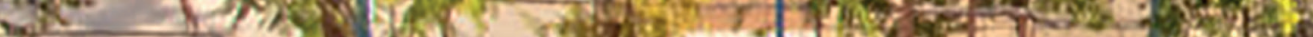




\section{Reflection on the role of nature and gender in con- temporary urban commons}

What emerges from the two case studies is a sensibility toward the construction of public spaces, where the project physically embodies and translates sustainability, social equity, humanistic and democratic values into design actions, directly influencing the space and the sensoriality of the public realm.

Framing Nature-based solutions and Gender Sensitive Approach as a new design method offers an opportunity to re-examine socio-environmental relations in an urban milieu, moving towards a holistic project able to build local knowledge encompassing sustainability in its triple notion: environmental, social and economic. The project for public spaces, therefore, takes on a new meaning in weaving the values for the society, to effectively build the framework of a cultural regeneration that goes beyond the physical intervention. These values refer to an ethical dimension of architecture, which embraces the concepts of care, for the environment and the community, of diversity within the ecosystem and the society, the right to the city and space and the need for ecological and social resilience. Starting possible to reflect on the new conditions of the urban landscape. In this sense, the paper recognizes the dual nature that characterizes the architectural domain nowadays; on the one side the architecture of the images, moving around starchitects and economic interests, on the other side the architecture of the people, parallel to the mainstream one, which embodies a value-driven approach aimed at creating more shared spaces both in the process and the future use.

Specifically, looking at the two projects, it is possible to describe the physical renegotiation of the urban common grounds (Ferguson, Urban Drift Projects, 2014), in which a humanistic architecture has the power to structure a social and environmental justice, as often claimed by the Pakistani architect Y. Lari.

From an environmental perspective, the two projects display how the collective use of these spaces can increase the ethical value of using NBS, influencing the adaptation of the urban landscape (Shaw, Colley, Connell, 2007) and defining a materialized ecological culture. What emerges is that NBS can be used not only as a technical tool but can define a new design approach, in which rethink the spatial system of neglected areas enriched with new ecological values.

Parallelly, the social values of the two projects investigated through a GSA, seem to translate into space 
Lefebvre's three rights: the right to urban everyday life, the right to simultaneity and encounters, and the right to creative activity (Lefebvre, 1968). These design processes present a shift in perspective that engages traditionally excluded populations such as women and children through co-creative processes building local knowledge and a sense of caring towards self-reliant communities (Shuman, 2000). What emerges is a strategy that takes shape within the communities of neighborhoods in "a communal enterprise", taking up the definition of architecture as "spontaneous and continuing activity of a whole people with a common heritage, acting under a community of experience" proposed by Pietro Belluschi (Rudofsky, 1964, pp. 3-4). In this sense, architecture is configured as a pedagogical tool, to frame more than a spatial regeneration, aiming to construct a cultural framework.

\section{Conclusion}

One of the main contributions of this work is to open up the discussion upon design strategies that could embody new values within the urban public space. Specifically, it links the regeneration of common spaces to broader sustainability challenges, including social inequalities and environmental hazards.

The essence of public space can be seen in this paper as the locus of a shared urban culture - based on collective values - in the coexistence with the other people, species and nature - in the notion of diversity, multiplicity where urban space plays as an active background. It is indeed a matter of proposing a sense of urbanity weaving the relationships among space, bodies and nature, materializing these threads in a physical palimpsest.

Rethinking the design action within the public sphere could help generate a new urban landscape, making closer the relation between the minerality of the city and the wilderness of nature, bringing new life to neglected areas. The construction of a new urban designed ground, redefining the inner landscape of the city, is connected to a new sensoriality of the urban landscape, having the possibility to rethink marginalized neighborhoods and give new values, both tangible and intangible, to the urban fringes, framing a physical regeneration and a cultural one.

As a consequence, this contribution argues that NBS should not be applied just as a technical solution, derived from the necessity of an urban adaptation, but as a more systemic and structured design discourse, able to introduce a new ecological sensibility. This paradigmatic shift in the use of NBS can be possible only through a proper involvement of the population, where NBS are tools to redesign the city but also to make people aware of the necessity to the right to nature. 
Considering this, nowadays, designers are called to rethink the public space, valuing it with new ecological and social aspects. This relevant challenge can lead urban areas to change uses and forms of public spaces, also in a perspective of long-term resilience. Ultimately it leads to a reflection on the role of the architect acting in marginalized contexts, whose aim is to create spaces where communities can participate as equals, introducing their innovation and knowledge. It's the task of the architect to show the possibility for a renewed space, convincing people of the values of architecture and its capability to restore a sense of belonging to the city and the environment. In this sense, we can state that this attitude would increase the willingness of people to actively take care of their living environment, where shared knowledge passed to the next generations would mean preserving the future. Implementing an ecological attitude to the project could help in making a closer relation between people and the environment and sensibilize society to the urgent issue of climate change. Accordingly, the article investigates co-creative processes that focus and involve especially the traditionally excluded social groups. It is clear how the construction of a new urban landscape acquires a pedagogical meaning, where the renegotiation of common spaces, unifying social and ecological perspectives, could estab-
In this sense, the construction of public spaces encompassing a series of intangible values, linked to an ethical dimension of architecture, results in the definition of a spatial palimpsest charged of multiple meanings that emerge in the ways of using the space itself and in its capacity to welcome the entire community becoming a place in which to identify. Thus, a new form of venustas emerges, which is related to an ideal of harmony, not only of proportions but of relationships, in a continuous tension between diversity, multiplicity and equality.

\section{Endnotes}

The authors thank Ecosistema Urbano and Equal Saree for allowing the use of graphic materials and pictures, of which the copyright holders remain. 


\section{Bibliography}

Avermaete T. 2009, Making Things Public: The Multi-Modal Public Space as a New Challenge for Dutch Design, in: Van Baar V., Van Meggelen B., De Rijk T., Dutch Design Yearbook, NAi Publishers, Rotterdam, pp. 57-68.

Bulkeley H. 2013, Cities and Climate Change, Routledge. Crutzen P. 2005, Benvenuti nell'Antropocene. L'uomo ha cambiato il clima, la Terra entra in una nuova era, Mondadori, Milano.

Deleuze G., Guattari F. L. 1987, A Thousand Plateaus: Capitalism and Schizophrenia, University of Minnesota Press, Minneapolis MN.

Ferguson F., Urban Drift Projects (eds.) 2014, Make_Shift City Renegotiating the urban commons, JOVIS Publishers, Berlin.

GIZ, UN-Habitat and GenderCC., 2015, Gender and Urban Climate Policy. Cender-Sensitive Policies Make a Difference. <https://gendercc.net/fileadmin/inhalte/dokumente/8_Resources/Publications/Guidebook_Gender_ and_Urban_Climate_Policy_June_2015.pdf > (20/10) Hawken P. 2017, DRAWDOWN. The Most Comprehensive Plan Ever Proposed to Reverse Global Warming, Penguin Books, New York.

Jacobs J. 2009, The death and life of great american cities, Einaudi, Cles.

Kabisch N., Korn H., Jutta S., Bonn A. 2017, Nature-based Solutions to Climate Change Adaptation in Urban Areas: Linkages between Science, Policy and Practice, Springer Nature, Cham (CH).

Lakoff A. 2007, Preparing for the next emergency, «Public Culture», vol. 19(2), pp. 247-271. <https://doi.org/ 10.1215/08992363-2006-035>.

Lefebvre H. 1968. Le droit à la ville, Anthropos, Paris. Matrix, 1984, Making Space: Women and the Man-Made Environment, Pluto Press, London.
Pasqui G. 2020, Socio-spatial inequalities in urban peripheries: the case of Italy, in Balducci A., Chiffi D., Curci F. (ed.), Risk and Resilience, Socio-Spatial and Environmental Challenges, Polimi Springer Briefs, pp. 79 - 94.

Rudofsky B. 1964, Architecture without Architects, an introduction to nonpedigreed architecture. MOMA, New York.

Sassen S., 2014, Expulsions: Brutality and Complexity in the Global Economy, Belknap Press, Cambridge (MA).

Shaw R., Colley M., Connell R., 2007, Climate change adaptation by design: a guide for sustainable communities, TCPA, London (UK).

Stavrides S. 2014, Emerging common spaces as a challenge to the city of crisis, «City», vol. 18, pp. 546-550.

Stiegler B. 2019, The age of disruption: Technology and madness in computational capitalism, Polity Press, Cambridge.

Terry G. 2009, No climate justice without gender justice: An overview of the issues, "Gender and Development», Vol. 17(1), pp. 5-18

Tronto J. C. 2005, An ethic of care, in Cudd A. E., Andreasen R. O. (ed.), Feminist theory: a philosophical anthology, Massachusetts: Blackwell Publishing, Oxford, UK Malden, pp. 251-263.

Zardini M. 2015, Toward a sensorial urbanism, «Lotus», vol. 157, pp. 63-73.

Women4Climate, 2019, Gender Inclusive Climate Action in cities. <https://w4c.org/sites/default/files/2019-02/ W4C_REPORT_Cender\%20Inclusive\%20Climate\%20Action\%20in\%20Cities_BD.pdf> (20/10). 